\title{
Design and Construction of Bamboo Stripping machine for Bamboo Basketry
}

\author{
Thanwamas Kassanuk ${ }^{1}$, Khongdet Phasinam ${ }^{2}$ \\ ${ }^{1,2}$ School of Agricultural and Food Engineering, Faculty of Food and Agricultural Technology, Pibulsongkram Rajabhat \\ University, Thailand \\ 1t.kassanuk@gmail.com, ${ }^{2}$ phasinam@psru.ac.th
}

\begin{abstract}
Handicraft of bamboo weaving has been a tradition that has been inherited for a long time, by using bamboo strips to weave into shapes to make tools and appliances. The bamboo strips are from dividing the longitudinal bamboo trunks into thin strips. In which most farmers will make the strips by hand by using a big knife or sharp objects. As a result, it takes a long time to prepare the bamboo strips to be used in the weaving work. There is also a risk of accidents from the use of sharp objects, including the size of the bamboo strips that is not the same size. This research aims to design and construct bamboo strips by dividing the research into 2 steps: 1) designing and constructing bamboo strips and 2) testing the operation of the stripping machine. The designed machine can be easily moved because it is a small and lightweight machine which is designed using a single-phase electric motor with a voltage of 220 volts, 250 watts, etc. Power to drive the roller through the transmission belt to convey bamboo parts through two 7-degree sets of blades with sharp angles that are placed horizontally. The first blade acts to separate the bamboo parts with the bamboo strips and the second blade acts to sharpen the bamboo strips. The results of the working test of the stripping machine by adjusting the blade angle at 1 and the level into 4 values that are 3, 4, 5, and 6 degrees, it was found that the machine was able to produce bamboo strips in size 1.47, 1.20, 1.97 and $2.27 \mathrm{~mm}$, respectively. The size of the punching line is suitable for weaving containers such as round bamboo basket, wicker basket, and bamboo basket, etc.
\end{abstract}

Keywords

Bamboo, Bamboo Strip, Bamboo Stripping machine, Bamboo Weaving

Article Received: 10 August 2020, Revised: 25 October 2020, Accepted: 18 November 2020

\section{Introduction}

Handicraft made from bamboo is a tradition that has been inherited for a long time, by bringing bamboo that is easy to find locally through the processing to produce an appliance in daily life with simple techniques combined with art. Traditions and cultures accumulate in the wisdom of each locality [1]. Handicraft made from bamboo is the introduction of bamboo strips to weave into shapes to be used as various appliances. The strips are thin strips of bamboo [2]. By taking the bamboo stems cut into pieces and reducing the size to thin strips along the length of the bamboo to be used in basketry such as chicken coop, hats, bags, and household appliances, etc. [3], [4].

Basketry in the area of Chom Thong sub-district, Muang district, Phitsanulok province is a group of farmers who are mainly engaged in agriculture and have a career after the end of the harvest season is the production of bamboo wicker because in an area suitable for growing bamboo and there are many bamboos. Wicker products are characterized by their beauty, durability, and uniqueness. Most farmers use big knives or sharp objects to sharpen the bamboo stems into thin strips by hand, resulting in a long time to prepare for slicing to be used for wickerwork. There is also a risk of accidents from the use of sharp objects including the size of bamboo strips that are not the same size [5], [6]. Therefore, this research aims to design and build a bamboo stripping machine. This will help reduce the time in the process of slicing preparation and getting quality bamboo strips, all strips are suitable and equal size, before being used for the next wicker production process.

\section{Research Objectives}

The objective of this research is to design and construction a bamboo stripping machine for bamboo basket.

\section{Research Methods}

Research for the design and fabrication of bamboo stripping machine. The researcher performed it in 2 steps as follows.

Step 1: Design and build a bamboo stripping machine, the design of bamboo stripping machine will apply knowledge of agricultural machinery [7] and mechanical design principles [8], [9]. So that the bamboo stripping machine should design to be able to move easily, strong, small, and lightweight. Using engineering programs to help design and drawing to see the layout and components of the machine [10]. This will enable the machine construction and component installation to be accurate and compliant as shown in Fig. 1 [11], with design details as follows. The structure of the machine is made of SS400 (mild steel), size $60 \mathrm{~cm} \times 16.5 \mathrm{~cm} \times 88 \mathrm{~cm}$, and equipped with 2 blades. The first blade, size $19 \mathrm{~cm} \times 7 \mathrm{~cm} \times 0.5 \mathrm{~cm}$, was installed in front of the machine to cut the bamboo. And the second one, size $12 \mathrm{~cm} \times 7 \mathrm{~cm} \times 0.5 \mathrm{~cm}$, was installed on the back of the machine in order to sharpen out the bamboo burrs. With a sharp blade angle equal to 7 degrees, which is positioned horizontally on the blade, leveling the blade with a screw. The power and transmission unit consists of a 250 watt motor that transmits power through a belt, gear, and chain to drive the shaft. And a cylindrical roller with a diameter of 6 $\mathrm{cm}$ and a length of $6 \mathrm{~cm}$ for moving bamboo strips from the front of the machine to the back (Fig. 2). 
Step 2: Checking the operation of the bamboo stripping machine. Therefore, the relationship between the work of different pieces created. The procedure is as follows:

1) Prepare one segment of the fresh bamboo by cutting out the middle of the bamboo and cut them to the same length as in Fig. 3.

2) Cut the bamboo into pieces of the same size as in Fig. 4 and measure the initial thickness of the bamboo pieces. After that, we started to experiment.

3) Adjust the angle of blade 1 (blade in front of the device) in the experiment, a total of 4 angles, that is, the blade angle is 3, 4, 5, and 6 degrees (Fig. 5).

4) Measure the speed of the rollers using a tachometer.

5) Feed the cut bamboo pieces through the front feeder of the bamboo stripping machine (Fig. 6) with 3 repetitions of 20 pieces each, each of which will produce 4 bamboo strips.

6) Measure the thickness of bamboo strips that have been sharpened with the second blade (the back blade of the machine) as shown in Fig. 6, then record the results and analyze the results.

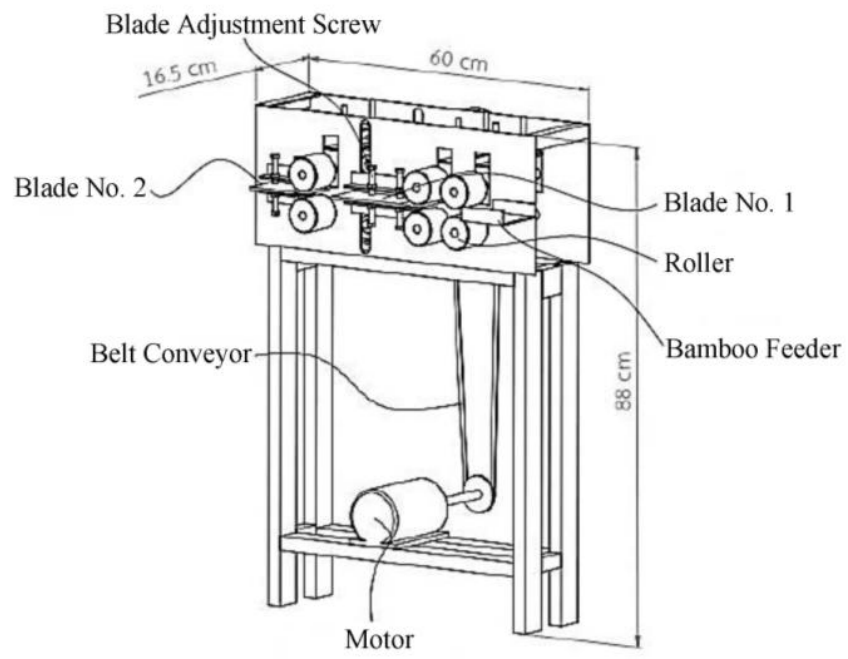

Fig. 1 The 3D model of the bamboo stripping machine

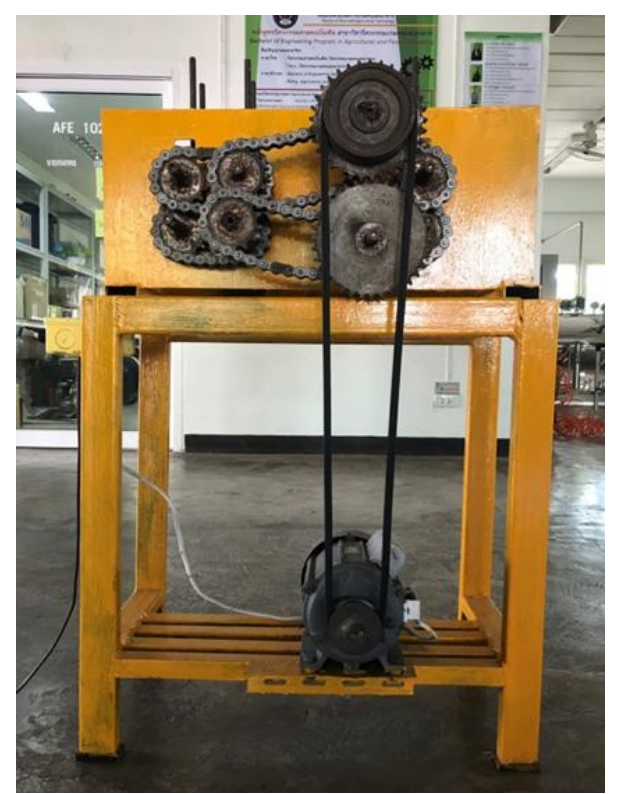

Fig. 2 Power unit and power transmission of the bamboo stripping machine

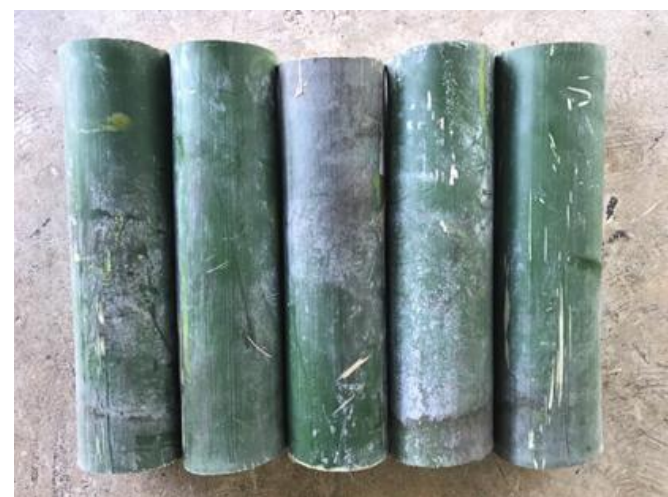

Fig. 3 A segment of bamboo

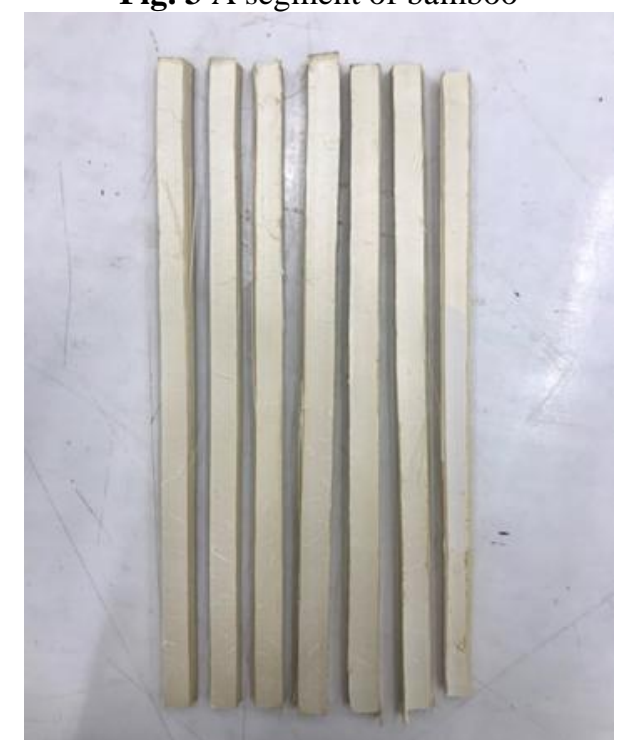

Fig. 4 Bamboo split for testing

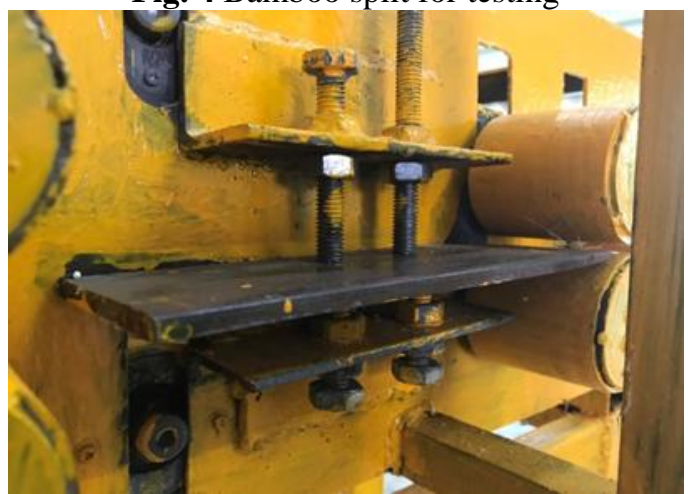

Fig. 5 Blade number 1 of the bamboo stripping machine

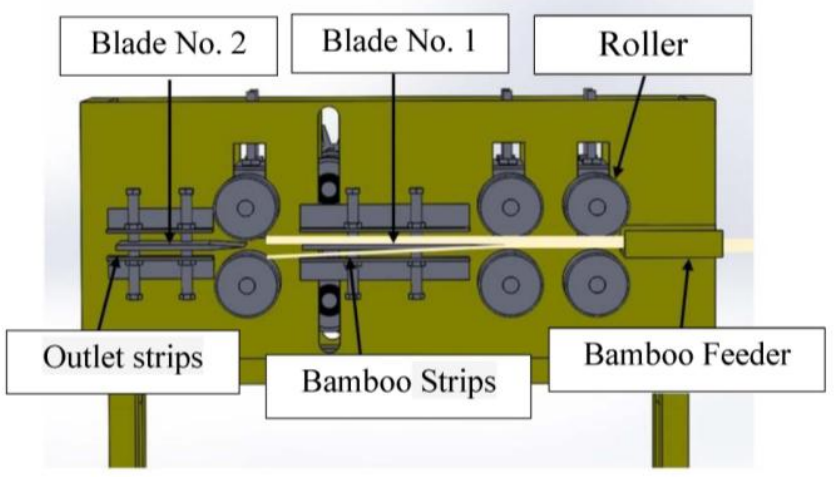

Fig. 6 Characteristics operation of the bamboo stripping machine 


\section{Results}

From the design and build of a bamboo stripping machine, a single-phase electric motor, 250 watts power and speed in the experiment $740 \mathrm{rpm}$. By the transmission motor driven through the belt to the mechanical set of the bamboo stripping machine and the machine has 2 blades. The first blade (front blade) serves to cut bamboo and the second blade (back blade) serves to sharpen bamboo. The experiment was performed using a single segmented bamboo, the length was $37 \mathrm{~cm}$, the bamboo was cut in width and thickness at an average of $16.45 \mathrm{~mm}$ and $8.95 \mathrm{~mm}$, respectively. The experiment was performed by adjusting the angle of the first blade, 4 types of knife angle, consists of $3,4,5$, and 6 degrees. From the experiment, it was found that the thickness of bamboo strips in each types of the blade is $1.47 \mathrm{~mm}, 1.20 \mathrm{~mm}, 1.97 \mathrm{~mm}$, and $2.27 \mathrm{~mm}$, respectively as shown in Fig. 7. From the graph, it can be seen that the blade angle of 4 degrees, bamboo strips have an average thickness of $1.20 \mathrm{~mm}$, which is the least thickness compared to the angle of other blades as in Fig. 8.

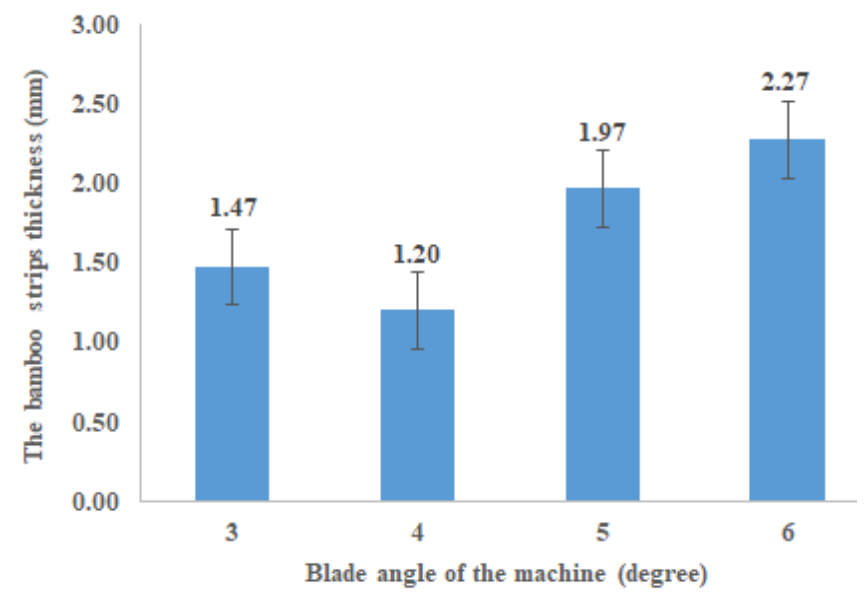

Fig. 7 The average of the bamboo strips thickness

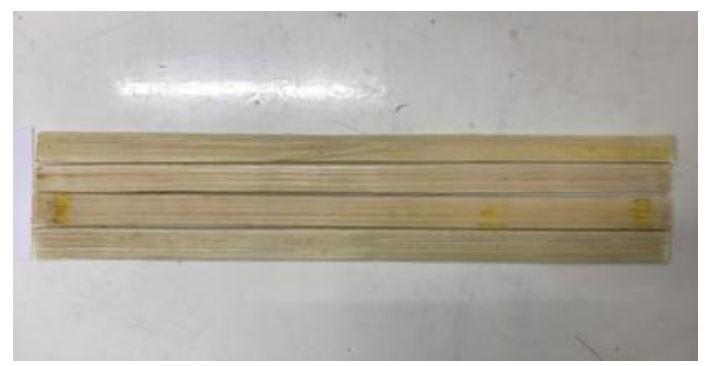

Fig. 8 Characteristics of the bamboo strips with the fist blade (4 degree)

\section{Discussions}

From experiment of the bamboo stripping machine operation, it was found that the thickness of bamboo strips when passing the first blade at an angle of 3 degrees was $1.47 \mathrm{~mm}$, an angle of 4 degrees was $1.20 \mathrm{~mm}$, an angle of 5 degrees was $1.97 \mathrm{~mm}$, and an angle of 6 degrees was 2.27 $\mathrm{mm}$. Due to the physical property of bamboo is composed of the longitudinal fibers of the trunk [12]. When in contact with the blade, the blade will shear, causing bamboo strips to decrease in thickness. On the other hand, the angle of the blade influences the shear of bamboo [13]. As a result, the thickness of bamboo strips during each blade angle was different. With the number of damaged bamboo strips decreased when the blade angle increases or the thickness of the bamboo strips increases because of the physical characteristics of bamboo that the fiber structure is longitudinal. When the blade shear and the appearance of bamboo strips will cause a change in the shape of bamboo strips in such a way that the bamboo does not fill the entire length. The suitable angle of the blade was 4 degrees and had an average thickness of $1.20 \mathrm{~mm}$, which is the lowest thickness compared to other blades and is the thickness of bamboo strips that are suitable for weaving containers such as round bamboo baskets, wicker baskets, and bamboo baskets, etc. The optimum thickness for bamboo weaving

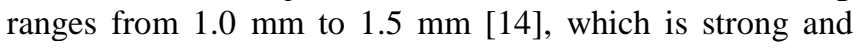
durable in use thickness.

\section{Recommendations}

\section{A. Recommendations for Practices}

This bamboo stripping machine was designed and fabrication to reduce the size of bamboo to the thickness that is suitable for use in bamboo weaving crafts and reduces the risk of accidents from the use of sharp objects.

\section{B. Recommendations for Further Research}

Designing and building bamboos for handicrafts made from bamboo. There should be additional testing of other factors affecting the quality of the bamboo strips, such as the motor speed, age of bamboo, and the moisture content of bamboo, etc. to make the research more complete.

\section{Conclusion}

This research presents the design and construction of a bamboo stripping machine. The machine is designed with a size of $60 \mathrm{~cm} \times 16.5 \mathrm{~cm} \times 88 \mathrm{~cm}$. It is equipped with 2 blades placed in a row. The first blade serves to cut the bamboo, size $19 \mathrm{~cm} \times 7 \mathrm{~cm} \times 0.5 \mathrm{~cm}$, and the second blade serves to sharpen the bamboo, size $12 \mathrm{~cm} \times 7 \mathrm{~cm} \times 0.5 \mathrm{~cm}$. A 250 watt AC electric motor was used as the power of the bamboo stripping machine, which the speed used in the experiment was $740 \mathrm{rpm}$. It was found that the angle of the first blade at 4 degrees, bamboo strips had the smallest thickness of $1.2 \mathrm{~mm}$. Compared with other angles of the blade, the machine can work continuously and bamboo strips is uniform in size, which the size of bamboo strips is suitable for wicker handicrafts such as round bamboo basket, wicker basket, and bamboo basket, etc.

\section{References}

[1] K. Pedcharat, W. Pinijvarasin and O. Panin, "The Wickerwork's Creative and Conservation of Traditional Bamboo Handicraft Center in Phanat Nikhom, Chonburi Province.", Veridian E-Journal, 
Silpakorn University, vol.11, pp. 198-212, 2018.

[2] Royal Forest Department, "Bamboo Basketry", Bangkok: AKSORN SIAM LTD., PART., 2004.

[3] T. Kornpitak, "A Bamboo Chopping Machine", Industrial Technology Lampang Rajabhat University Journal, vol.7, pp. 16-24, 2014.

[4] Community Forest Management Office. (2008). Weaving a Mackerel Basket with Bamboo. Royal Forest Department., BKK. [Online]. Available: http://www.openbase.in.th/node/5957

[5] N. Jadjang, "Bamboo Stripping machines for Mackerel Basket Wicker", 21st-22nd Mar. 2013, Rajamangala University of Technology Isan Surin Campus, Surin, Thailand.

[6] G. Keshav and M. Damodaran (2013). "Design and Prototyping of a Low-Cost Manually Operated Bamboo-Cored Incense-Stick Making Machine", Proceedings of the 1 st International and 16th National Conference on Machines and Mechanisms, IIT Roorkee, India.

[7] J. Langkapin, "Theory of Agricultural Machines", Bangkok, Triple Education Co.,L.td, 2015.

[8] V. Ungbhakorn and C. Thanadngarn, "Mechanical design vol. 1", Bangkok: SEEDUCATION Public Company Limited, 2013.

[9] V. Ungbhakorn and C. Thanadngarn, "Mechanical design vol. 2", Bangkok: SEEDUCATION Public Company Limited, 2013.

[10] P. Suwan, "Solidworks 2014 For Engineering Design", Bangkok, Witty Group, 2015.

[11] T. Kassanuk and K. Phasinam, "Design and Construction of Water Hyacinth Chopper", RMUTI JOURNAL Science and Technology, Vol. 13, pp. 57-68, 2020.

[12] S. Ithisoponakul, A. Meemon and S. Pramoonmak, "A Machine for Split the Bamboo Scraps from Glutinous Rice
Roasted in Bamboo Joints", Research Report, Pathum Thani: Faculty of Engineering, Rajamangala University of Technology Thanyaburi, 2010.

[13] Y. Sengdang and K. Chamniprasart, "Study of the Pararubber Tapping Knife Angle by Using Electrical Motor", 15th17th Oct. 2008, Thammasat University, Pathum Thani, Thailand.

[14] Community Development Department Office of Chaiyaphum. (2016). Basketry. Community Development Department, Ministry of Interior., CPM. [Online]. Available:

https://chaiyaphum.cdd.go.th/services/page /20 